\section{NOTES ON THE DEMONSTRATIONS OF METHODS IN GASTRIC THERAPEUTICS. ${ }^{1}$}

BY FENTON B. TURCK, M.D.,

RZOFESSOR OF GASTRO-ENTEROLOGY IN THE POST-GRADUATE MEDICAI SCHOOL, CHICAGO; MEMBER OF THE AMERICAN GASTROENTEROLOGICAL ASSOCIA'TON, ETC.

THE first essential element of rational therapeutics is a correct diagnosis based on the history of the case, its symptoms as observed by the physician, and thorough and exact methods of clinical examination. The eridence of the anamnesis and rational symptoms is as important in its way as any part of the general examination by means of such instruments of precision as the microscope, the test-tube, and all other paraphernalia of the medical laboratory and ought not to be undervalued. After all the data from all these sources are obtained he is best able to correctly diagnose the case whose judgment, ripened by study and experience, can best select and compare all the facts, giving each one its proper value, and then can estimate and harmonise the whole. The chemical methods of examination in gastric diseases have been carried by the Germans to an extreme refinement. Since Ewald first introduced the soft rabber stomach-tube this has been most extensively utilised in variously modified forms for both diagnostic and therapeutic purposes. The German literature on the chemical examination of the gastric contents by the use of the tube would fil many volumes and yet after twenty years' experience we find that little dependence can be placed upon the chemical methods and their results for diagnostic and therapeutic purposes as compared with those of directly mechanical methods. In $1894 \mathrm{I}$ had the honour to present before the International Medical Congress in Rome a method for examining the stomach that looked more into the physical condition of the organ than into the chemistry of its contents. Demonstrations of the method were also made in that same year at Vienna, Berlin, and other cities. ${ }^{2}$ Without going into any criticisms of the various other instruments and methods devised for the purpose of determining the position and physical condition of the stomach, some of which methods have done, and undoubtedly still do, great service in the hands of sufficiently skilled and experienced physicians, the medical profession is, I think, still in want of a rapid and practical method by means of which the position, size, and motor power of the stomach can be determined with accuracy and in all varieties of morbid states.

One of the instruments and methods there described for the frrst time in Europe, somewhat modified and considerably improved during the four intervening years of clinical practice and experimentation, I now present to you (Fig. 1).

Frg. 1.

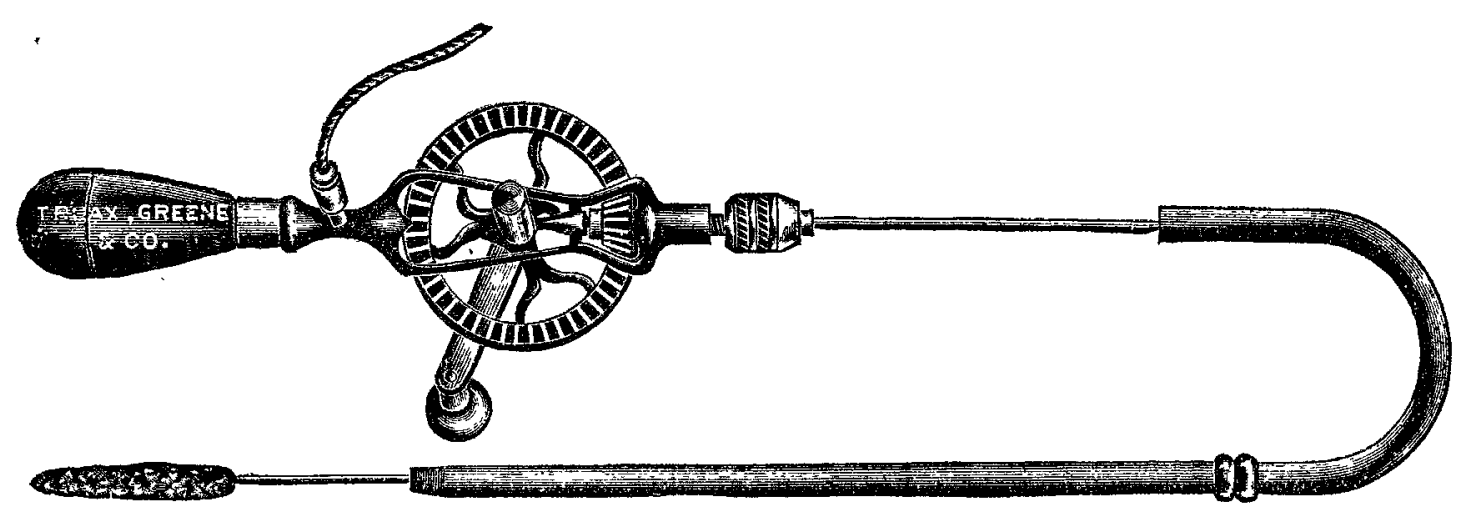

The gyromele or revolving sound, with sponge attached to the cable.

The instrument I have called the "gyromele," though for most of you the term "revolving sound" may be more familiar and descriptive. It consists of a flexible rubbercoated steel cable, to one end of which is attached a soft sponge and to the other an apparatus for producing revolutions, not unlike a surgical drill. When the instrument is to

1 Alstract of Demonstrations and Lectures given at St. George's $H$ uspital, London, on August 8th, 9rh, and 10th, 1898. 2 Wiener Klinische Wochenscirift, 1895, Nos. 1 and 2. be used the cable is first slipped through a rubber tabe long enough to reach through the cosophagus to the cardiac opening and cable and tube are then introduced into the stomach. The cable and sponge are then pushed further down into the stomach and the drill is attached to the external end. As the now rotating and vibrating cable is pushed further down the sponge glides along the greater curvature, the pylorus, and the lesser curvature; while the cable adjusts itself to the shape of the stomach, and its motions can be distinctly felt by the hand upon the abdo. minal wall.

From the evidence of several hundred cases upon which the gyromele has been used both for diagnostic and therapeutic purposes during the last four years I believe that we can safely conclude that by means of this instrument it is possible to determine with practically absolute certainty-1. The exact outline of the stomach on the abdominal walls, the greater curvature, the lesser curvature, the fundus, and the pylorus. 2. The character of the stomach walls: (a) any considerable thickening of the walls is unfailingly discovered because of the varying ease and plainness with which the sponge revolved against the wall can be felt on the outside; and $(b)$ the distensibility of the stomach can be more readily and more accurately determined by simply using cables of different degrees of flexibility than it can be determined by any other method. From its distensibility the motor power can be quite accurately estimated in cases where there is no pyloric obstruction, as has been repeatedly found by experiment. The pyloric obstruction if present is disccvered in the process of the sounding of the stomach, pylorus, and duodenum. 3. In addition to the above complete diagnosis of the physical condition of the stomach the gyromele has been found to be an unfailing means of discovering atrophy and, indeed, of distinguishing atrophy from functional achylia. This is due to the fact that the revolving sponge is quite as effective as any test meal for stimulating the secreting glands to almost immediate activity. On withdrawing the cable the sponge is found saturated with the gastric contents and this furnishes ample material for bacteriological and qualitative chemical tests. If the gyromele is allowed to remain in the stomach for a few minutes (which does not inconvenience the patient) the stomach contents will within fifteen minutes invariably contain $\mathrm{HCl}$ unless there be atrophy of the $\mathrm{HCl}$ secreting cells. In order to thus determine with certainty the presence or absence of cellular atrophy the gyromele is revolved a little longer than usual and the stomach contents are examined about fifteen minutes after the withdrawal of the gyromele cable. The contents will then invariably contain hydrochloric acid unless there be glandular atrophy.

Before proceeding to practically demonstrate the use of the gyromele for these purposes it may be as well to call attention to the objection which has been raised against it by some on the ground of danger to the patient. This objection is wholly unwarranted so long as there is no case on record where the gyromele has produced injury to a patient. Neither in private practice nor in the large hospital practice of myself and my students has there ever occurred such a case and I have yet to hear of it from any other source. The gyromele is, in fact, less dangerous than the universally used stomach tube for the simple reason that the end of the cable is of sponge and this when wet, and especially when covered with mucus, is as soft and slippery as the mucous membrane itself. The reason for ascribing such danger to the use of the revolving sound must be the fact that it can be so easily and distinctly felt through the abdominal walls, but this is due simply to its rapid motions and vibrations which are very perfectly transmitted through the abdominal tissues and the patients soon become so accustomed to the gyromele treatment that its use does not produce any marked feelings of distress. In addition to the above I must also, in justice to myself, defend my priority in the introduction of the flexible sound as against the claims of Dr. Kuhn of Giessen. The flexible 
revolving sound was used and described for the first time in Europe by me in 1894 as has already been stated. Its utility for sounding all regions of the stomach and duodenum as well was clearly set forth in my demonstration at Rome in that year, while Dr. Kuhn's first publication on this subject appeared in 1896. Since Dr. Kuhn in his publication makes no mention of my much earlier work on the subject it must be supposed that he knew nothing of it at the time. Be this as it may, the fact remains that he has not added a single new feature to the instrument which was shown in 1894 and his claims to priority either of the instrument or of any method of using the same is, to say the least, in every essential unwarranted. ${ }^{3}$ We will now proceed with the demonstration.

CASE 1. (August 8th, 1898).- -The patient, a woman, aged fifty-one years, began to have stomach trouble about a year ago and since that time has continually grown worse until she at present is so weak that she cannot leave her bed. The food that she eats, as well as the gastric secretions, seem to accumulate in the stomach until she is forced to vomit so as to obtain some relief from her distress. The vomited matter shows all the characteristic indications of retention. Examination shows general emaciation with panniculus adiposus absent. There is no cachexia. 'The chest organs are almost negative as regards physical signs. The abdomen is retracted in the left epigastrium and in the umbilical regions a bulging may be observed. This is due to the enlarged stomach as is shown by slight peristaltic movements, which can be recognised. Yesterday, three hours after a meal consisting of beef and bread, we found on passing the "intragastric reagent capsule" 4 into the stomach that the Congo paper and the dimethyl amidoazo benzol paper showed no free $\mathrm{HCl}$, while the litmus paper indicated a faintly acid reaction. To-day on withdrawal of the stomach contents ten hours after a meal we find again no free acid and we do find quantities of food particles. We now introduce a very flexible gyromele with the patient lying on the bed, and by the palpating the revolving sound upon the abdominal wall we locate first the greater curvature at the umbilical line, and by pushing the cable further into the stomach until the revolving sponge impinges against the lesser curvature we find it located just below the border of the left lobe of the liver. On withdrawing the gyromele and testing the liquid which can be obtained by squeezing the sponge we find again that there is no $\mathrm{HCl}$ present in the stomach. The outline and position of the stomach as thus determined are shown by the diagram (Fig. 2).

FIG. 2.

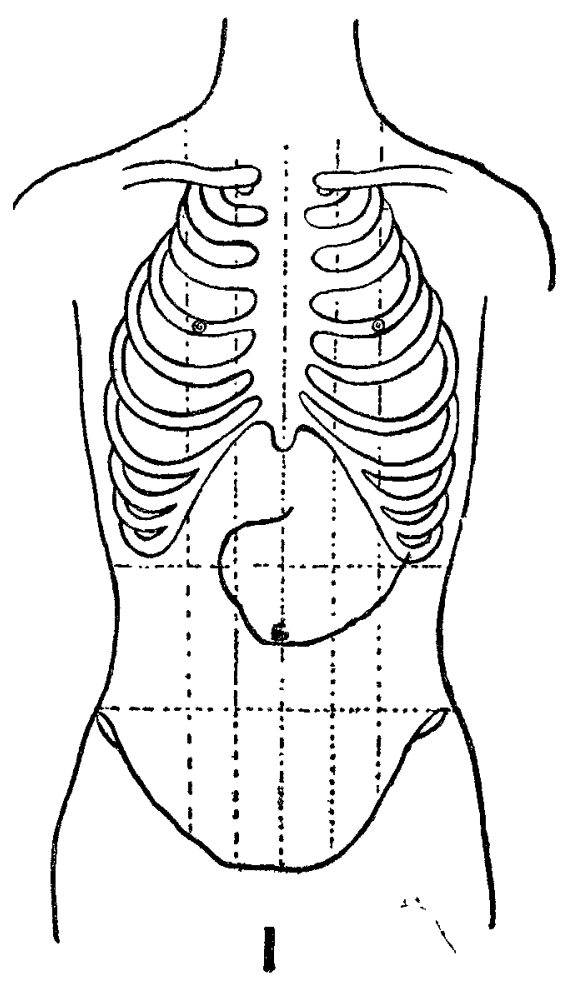

The outline of stomach as given by the movements of the light flexible cable.

In order to determine the degree of distensibility of the stomach we now pass in a gyromele having a somewhat less

3 Turck: Die Priorität der Sondirung von CEsophagus, Magen und Eingeweide mittels der Gyromele (biegsamen Revolvirsonde), Oentral blatt für Innere Medicin, No. 8, 1898 flexible cable than the one just used and again determine the outline of the stomach by palpating the revolving and vibrat. ing sound. This time with the patient sitting upright we find the greater curvature below the umbilical line and quite near the hypogastric line while the lesser curvature can be distinctly outlined just above the epigastric line. As shown with this second cable (see Fig. 3) we find that the stomach

FIG. 3.

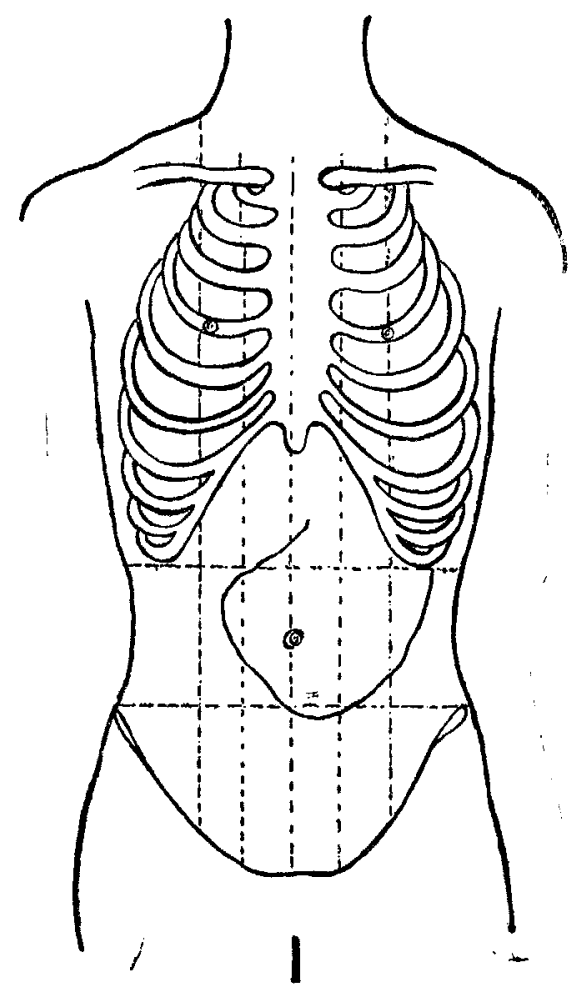

The outline given by the movements of the less flexible cable.

is only slightly dilated but that this is a case of marked gastroptosis with very lax ligaments, the stomach being freely moveable in its position. The long duodenal cable is next introduced for the purpose of sounding the pylorus. The sound is obstructed as it reaches the pylorus and further pushing only elicits signs of pain. The tip of the revolving sound can easily be recognised and the palpation indicates a hardened and thickened pylorus, but no tumour can be felt.

From the tests thus made we arrive at the following diagnosis:-1. Absence of free $\mathrm{HCl}$ after various test meals together with the failure of the gyromele to produce a secretion of the acid would indicate atrophy of glands. 2. The slight dilatation of the stomach, together with the ease with which the whole viscus can be pushed downwards, as shown by the use of cables of different flexibility, indicates the presence of gastroptosis and the thickened walls show hypertrophy. 3. The long retention of the food indicates either motor insufficiency due to myasthenia or pyloric obstruction and as the duodenal sound indicates a hardened and thickened pylorus we conclude that this is a case of stenosis pylorica. In view of the fact that the pyloric obstruction, notwithstanding the marked hypertrophy, is almost complete I recommend immediate operation.

[Through the courtesy of Dr. Ewart, the attending physician in charge of the case, the following hospital report has been received:]

"Operation was performed by Mr. Jaffrey on August 17th. No outlying mass of cancer or glands could be felt. The stomach was of moderate size with thick muscular walls and did not reach below the umbilical level. Owing to its dropped state it could be easily pulled throngh the incision as well as the pylorus. The pylorus and its vicinity were free from peritoneal adhesions or thickenings. There were a few superficial pyloric venules and minute whitish specks but no important engorgement. The gall-bladder was greatly distended with bile. Marked thickening could be felt not only at the pylorus but $1 \mathrm{in}$. or $2 \mathrm{in.}$ along the duodenum and 2 in. or 3 in. along the lesser curvature. This decided $\mathrm{Mr}$. Jaffrey to prefer gastro-jejunostomy to pyloroplasty and this was accordingly performed with satisfactory results, the patient doing well for two days. On the third day she began to vomit. Exhaustion set in on the fourth day when she died. At the necropsy no tympanitis or peritonitis could be found. The external and the stomach wounds were sound. The thickening which had been felt was found to be almost 
entirely muscular, traversed from within by a few fibres from a thin radiating deposit with white fibrous tissue in the submucous layer. In connexion with this the mucous membrane at the pylorus and for 1 in. beyond was atrophied, glistening, and striated.

"There appeared to be nothing in the case, judging from these appearances, incompatible with complete recovery from the gastric dilatation, as well as the gastroptosis, had the patient's strength been equal to the surgical ordeal. The case tends to show how slight may be the impediment which ieads to these fatal results."

From what has just been said in regard to the use of the gyromele it must not be inferred that this instrument is the - one thing or the only one to be used in the diagnosis of diseases of the stomach. On the contrary I would insist that the successful diagnostician of these diseases must have at his command all the methods which have been shown to be waluable, and to such an extent that he will know how to vary them in their application to the "needs of each particular case. The test meals and the soft rubber stomach tube, for example, are devices for which the profession must gratefully remember their originators. Moreover, cases arise where the stomach tube as well as the gyromele fail us for the simple reason that we dare not use them. Various more or less successful devices have been got up to meet the needs of such cases. ${ }^{5}$ In how far these meet the requirements of Furopean practitioners I do not know, but I have found the following method to be of great value where the stomach tube cannot be used. In the Journal of the American Medical Association for April 23rd, 1898, I presented a device called "intragastric reagent capsule" which does possess decided advantages over the older sponge tester, silver bucket, pith-pellets, \&c. The intragastric reagent capsule

FIG. 4.

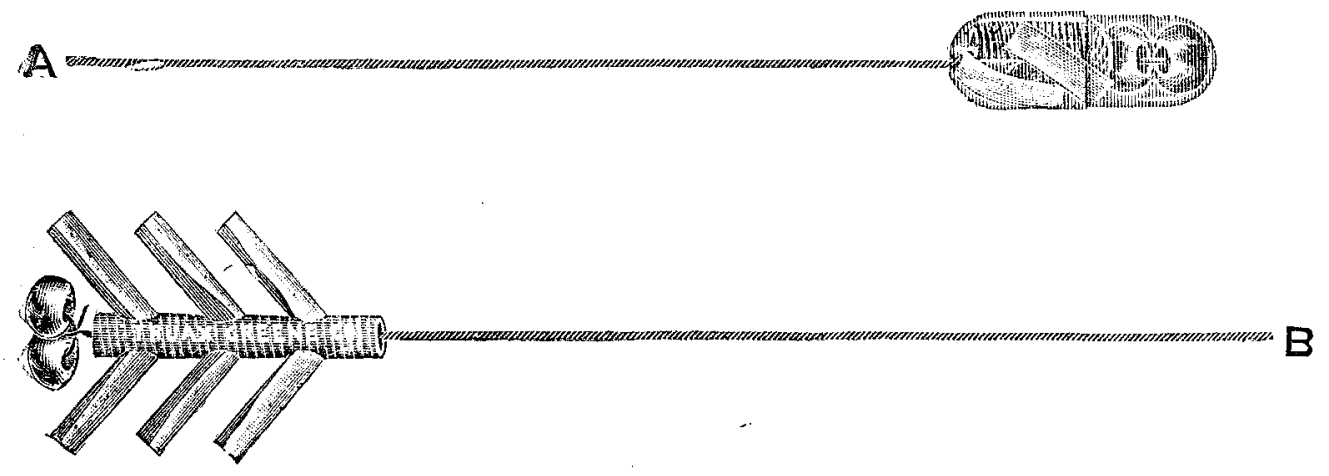

$\Delta$, the intragastric reagent capsule, containing the indiarubber tube, reagent papers, and lead shot, as shown in $\mathrm{B}$

contains a small piece of rubber drainage tube about an inch in length slit so as to carry three test-papers. Through the tube is passed a silk thread carrying a goodsized lead shot at the end. The tube with test-papers and the shot are enclosed in an ordinary gelatin capsule. The capsule is easily swallowed and sinks readily to the bottom of the stomach. In five minutes the capsule will be dissolved, the test-papers will be saturated, and the tube will be filled with the stomach liquid that will not run out because the lower end will be closed by the shot. When the string is withdrawn the three test-papers coloured with litmus, *Congo red, and dimethyl-amidoazo-benzol paper respectively will at once indicate the chemical nature of the stomach - contents. The liquid in the tube can be used for duplicating the tests or for microscopic examination.

CAss 2.-This patient, a robust-looking young woman, aged twenty-two years, has just entered the hospital with the diagnosis of ulcer of the stomach. She complains of a penetrating pain in the left epigastrium, near the costal arch. She has had frequent spells of vomiting, these sometimes passing into paroxysms of pain, when the vomited material would contain more or less blood. The physicians in charge thave on the strength of these symptoms, upon which Brinton has laid especial stress, made a diagnosis of ulcer and have referred the case to this hospital for treatment. It is easier to describe characteristic symptoms of ulcer of the stomach than to make the diagnosis at the bedside. In at least 75 per cent. of the cases of ulcer there is an increase of the

5 Edinger: Deutsches Archiv fir Klinische Medicin, Band xxix., p. 555. Finhorn: Medical Record, July 19th, 1890. Spaeth: Minchener Medicinische Wochenschrift, Band xxxiv., 1897, p. 1011.
$\mathrm{HCl}$ and the other 25 per cent. show hypochlorhydria or very rarely a case of achylia. Therefore, if the excess of $\mathrm{HCl}$ is found together with the above three characteristic symptoms, localised pain, vomiting, and hæmorrhage, the diagnosis of ulcer would be very much strengthened. But we are prevented from determining the state of the gastric secretion by the danger of passing the stomach tube and by opposition from the patient. We may, however, have the patient swallow this intragastric reagent capsule which is neither more dangerous nor more difficult to swallow than a bolus of food. The capsule is weighted inside by means of a good-sized shot and its rapid entrance into the stomach is hereby ensured. We wait five minutes, allow the capsule to dissolve so that the test-papers may come in thorough contact with the gastric contents. On withdrawing the capsule test-papers we find that they are unchanged and that there is therefore no hydrochloric acid present in the stomach; the litmus paper shows there is in fact no acid reaction whatever. Closer investigation now reveals the fact that while the pain is more intense in the region of the costal arch it is also quite diffused over the epigastric region. We also learn that the pain is not particularly increased by taking food and that the hæmorrhage was at no time very profuse. These facts tend to throw considerable doubt on the diagnosis of ulcer. Now since by the use of the capsule the patient's opposition has been lessened we may now pass the stomach tube and on withdrawal of the contents we find that there is no acid present. Having thus found the presence of ulcer highly improbable we must look for other causes of the slight hæmorrhage which has occurred, and as rales can be heard in the apices of the lungs, especially in the right apex, we must consider the possibility of pulmonary hæmorrhage and if this be excluded we may diagnose the hæmorrhage as pharyngeal or cesophageal. Under these circumstances we certainly have no reason to consider this a case of ulcer and may recommend a more vigorous line of treatment.

The following report has since been received (September, 1898): "I may add to the report concerning the young woman that she continued to improve, gained weight as well as strength, and lost the slight rîles that we had discovered at the right apex.-Wm. Ewart."

Therapeutics.-The first essential element of rational therapeutics, as was mentioned at the beginning, is a correct diagnosis and these demonstrations illustrate in a measure what was said in regard to having a sure command of the chemical and still more of the physical factors that must be considered in the accurate diagnosis of gastro-intestinal disorders. What is true of diagnosis is emphatically true in therapeutics of stomach diseases. Chemical reagents, medicines, have their proper uses and no conservative physician would attempt to do without them. Medical men are, however, at present agreed that the physical condition of the stomach is of far greater importance than its secretory function and the pathological disturbances are largely mechanical, such as motor insufficiency. The logical outcome of this fact are the modern attempts to improve this physical condition by physical means, such as lavage, massage, exercise, "electrisation," and a variety of mechanical stimulating devices. The gyromele described above is most useful as an instrument of diagnosis. In addition, however, it has a therapeutic value which can scarcely be over-estimated. It removes mucus and other adherent débris from the entire inner gastric surface and by subsequent use of the needle douche ${ }^{6}$ the stomach can be cleansed far more perfectly than by any other method. By means of the gyromele any desired antiseptic can be applied to the entire surface of the stomach; the combined rotatory-vibratory motions of the gyromele give at the same time a very stimulating massage to every part of the organ. That the massage given by means of the gyromele must be very effective is evident when we consider that the mere contact with solid food in the stomach is sufficient to stimulate the circulation in the gastric walls and to produce the muscular contractions by which the food is churned during cligestion. A systematic 
massage by means of the gyromele improves rapidly the motor power and the circulation of the stomach and these results are in turn followed by a diminution of the mucus and often by a restoration of the secretory function to normal conditions. In addition to these patent advantages of this instrument it has been found to act better than any other electrode for electrical stimulation because it permits direct application at any desired area of the stomach walls. For these reasons the gyromele is used in my private and hospital practice and clinics more extensively than any one other device.

The intragastric resuscitator which $I$ show here needs but little description (Figs. 5 and 6 ). It consists simply of a double stomach tube ${ }^{7}$ to one end of which is attached a soft rubber bag, ${ }^{8}$ which was originally devised for the purpose of reducing surgical shock and collapse. ${ }^{9}$ The bag when collapsed fits closely around the stomach tube and is easily introduced into the stomach. Its use and purpose in gastric therapeutics can be illustrated upon the following case.

CASE 3.-This patient, a keeper of a publichouse, forty-two years of age, is suffering with Raynaud's disease. The patient is unable to walk and for the last six weeks has been confined to his bed. The hands are pale (local syncope) and the feet are bluish (local asphyxia). There is a complete absence of radial pulse and the heart beat is small and feeble. The abdominal physical symptoms are negative. The temperature in the axilla is $98.8^{\circ} \mathrm{F}$., in the rectum it is $99.2^{\circ}$, and on the skin (inner side of the calf) $92 \cdot 1^{\circ}$. The patient was given a bath about an hour ago; we now introduce the intragastric resuscitator. The double tube with attached rubber bag is passed into the stomach and we pass a continuous current of water through the tube and bag, beginning with water of $125^{\circ} \mathrm{F}$. and gradually increasing its temperature to $130^{\circ}$. In surgical shock we use temperature as high as $135^{\circ}$. The water is cooled in the stomach by the rapid transmission of heat to the tissues, but as the current of water is continuous the high temperature is maintained and this acts as a powerful vaso-motor stimulant upon the resophagus, the stomach walls, and upon the splanchnic area, and also reflexly on the heart. As the oesophagus and gastric walls become heated as well as the great vessels in proximity the warmed blood is rapidly carried to the periphery by the circulation, stimulating the cells and producing a dilatation of the previously contracted peripheral arterioles. The congestion of the splanchnic area is

7 For description of Turck's double tube see the Journal of American Medical Association. June 22nd, 1895, and American Medico-Surgical Medical Association, J
Bulletin, July 1st, 1895.

8 Journal of American Medical Association, June 11th, 1896. 8 Turck : Surgical Shock, ibid., June 19th, 1897. also rapidly reduced and a more abundant supply of blood is carried through the heart. The heart beats in consequence become stronger, the hands and feet begin to show warmth and the improved colour of the skin can be observed as the treatment is kept up. This is particularly noticeable under the finger nails where the normal pink shade is gradually replacing the pale whiteness observed before. we began the treatment. Half an hour's treatment is: sufficient. We syphon off all the water from the bag and remove it and the tube from the stomach. The. extremities now show warmth, the colour of the hands and feet is much improved, the eyes are bright, and the face presents quite a rosy tint. The patient feels stronger, is able to get out of the bed, and walks supporting himself
FIG. 5 .

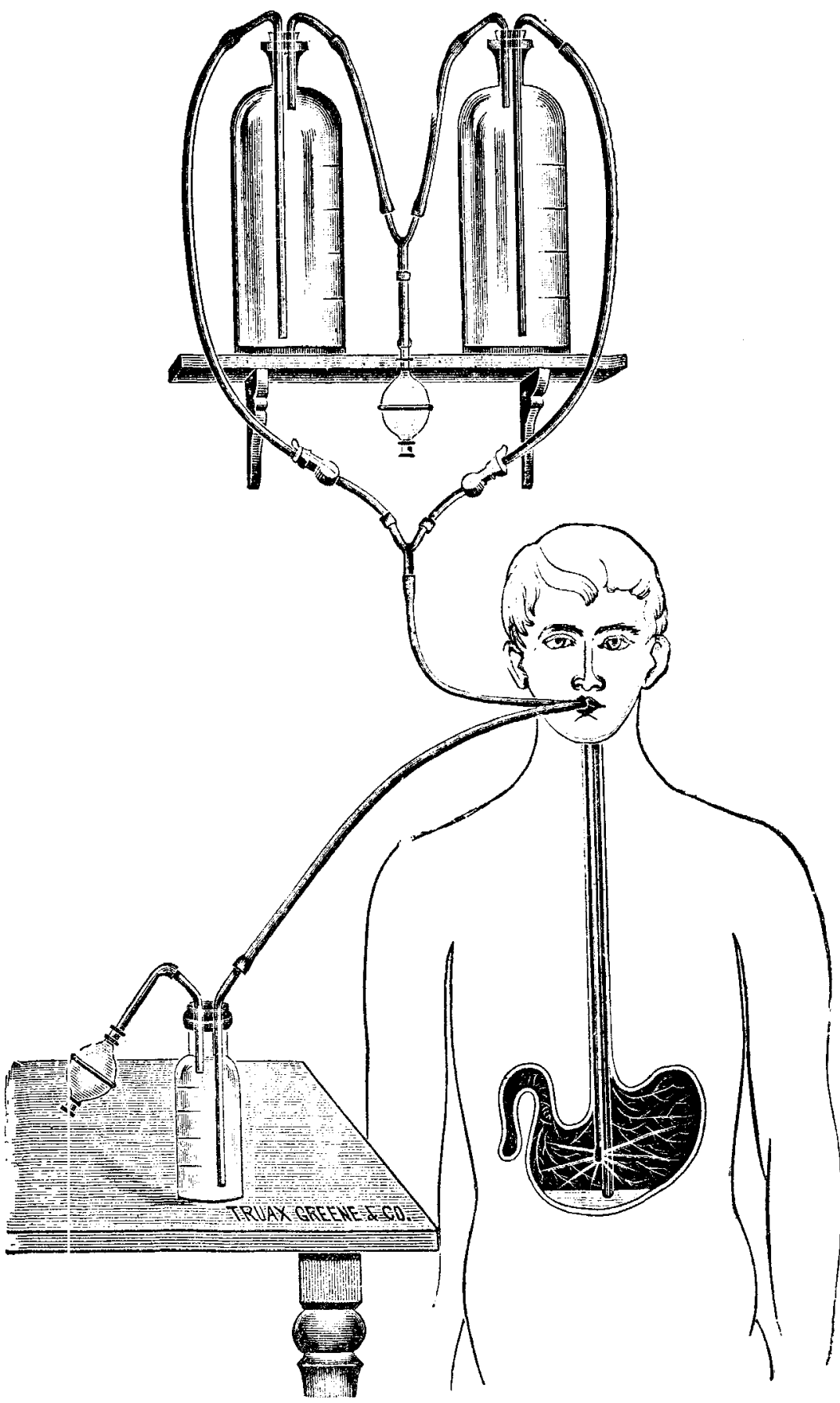
The intragastric resuscitator; apparatus for the neelle douche and for washing
out tne stomach. to a rolling-chair, and seems in general to be very much strengthened. The heart area is normal, the beat is full and strong, and there is no reduplication of the heart sounds. The temperature one hour after treatment per rectum is $100^{\circ}$, in the axilla it is $96.6^{\circ}$, and on the skin it is $95.5^{\circ}$. (According to a later report the patient left the hospital much better and stronger. This case was used for the purpose of demonstrating the method of using the intragastric resuscitator and to show its physiological effects.)

The advantages of the intragastric resuscitator are : -1 . The heat is applied in a uniform and diffuse manner of much higher temperature than dare be used with water in direct contact with. the mucous membrane. The temperature here used (from $130^{\circ}$ to $135^{\circ}$ ) is in most cases necessary in order to produce the desired stimulation. 2. The exhaustion produced by passing large quantities of warm water directly into the stomach (which dilates the splanchnic vessels) is avoided, while the hot water used by the above method produces stimalation of this area without exhaustion. 3. The removal of the necessary secretions and nutrient material is entirely avoided. 4. The degree of temperature as welli as the quantity of water used within the bag is under the complete control of the operator.

Fleiner refers to lavage as follows: "The changing distension and emptying of the stomach act upon the walls of the stomach like local gymnastics. Motility is rapidly improved, atony disappears," \&c. (Quoted from Baruch's "Principles and Practice of Hydrotherapy," 1898, p. 280. A more effective and satisfactory method for giving the stomach this exercise has been used for some years in my clinics and private practice. The alternating distension and contraction of the stomach is more perfectly accomplished by the use of air instead of water.

Pneumatio gymnastios of the stomach.-By this means the distension is more uniform in all directions and the objections to the heavy load in an already prolapsed dilated, and weakened stomach is entirely avoided. Moreover, 
the dilatation by the use of water takes place in one direction only-namely, downwards-while the air acts equally on all sides giving all the musculature of the stomach that most effective extension and contraction which is known to be so valuable to weakened muscles of other parts of the body. I had the honour to present at the recent meeting in Edinburgh by invitation of the British Medical Association a full description with reports of experiments and cases of the apparatus and methods used to produce pneumatic gymnastics. ${ }^{10}$ The method brietly is as follows. A double stomach tube is introduced into the stomach and is connected on one side with a manometer and on the other with a compressed air cylinder. The cyclinder has previously been filled with air at rather high pressure ( 3 or 4 atmospheres) by means of a small hand-pump. By then opening a stopcock of the cylinder air is allowed to distend the stomach until the manometer connected with the closed exit tube indicates the desired pressure. The stopcock is here closed and the exit tube is opened. The compressed air in the now quite distended cavity rushes out and the gastric muscles centract vigorously, aided by the contractions of the abdominal muscles. ${ }^{11}$

This exercise can be repeated from twenty to thirty times in the course of a few minutes and a regular course of this exercise will frequently produce a very rapid improvement in the motor power of the organ even after other methods of treatment have failed. Another most remarkable effect of this IIIG. 6.

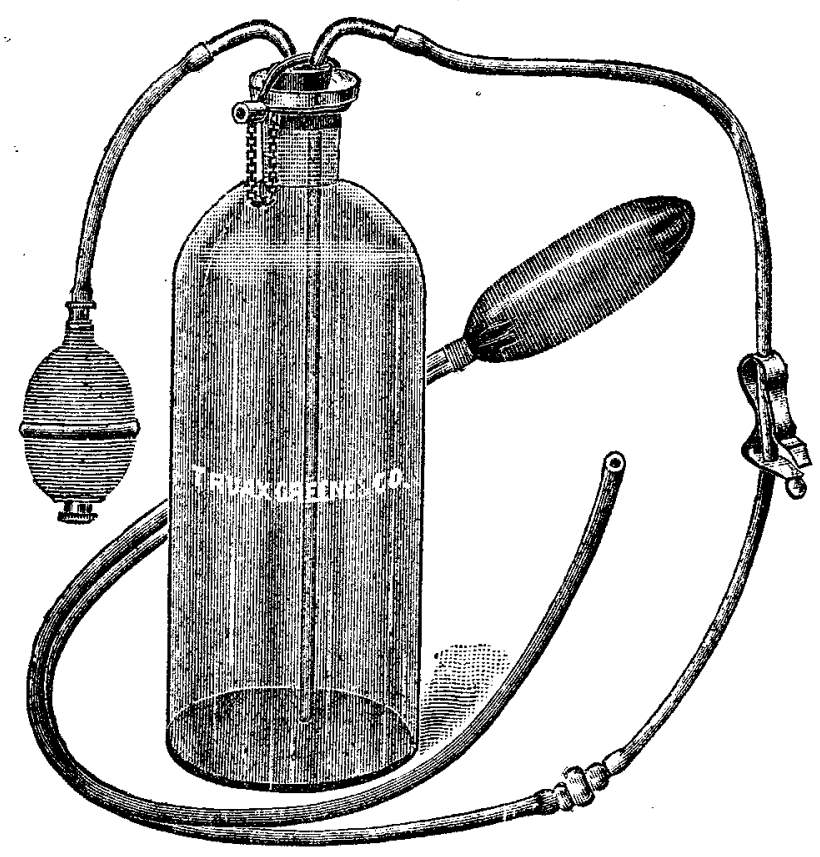

The intragastric resuscitator; the gastric end of the double tube covered by the dilateable soft rubber bag.

treatment is the improvement of the local and general circulation noticed very early even by the patients. The experiments upon animals just referred to demonstrate a marked effect upon the splanchnic and ultimately upon the peripheral circulation. By passing the air through heated water (from $50^{\circ}$ to $65^{\circ} \mathrm{C}$.) we can introduce heated vapour at a controlled temaperature into the stomach. The effect is most remarkable and the method has none of the disadvantages of lavage.

In the above are briefly indicated the most important original methods of diagnosis and therapeutics which are constantly used in our clinics and practice. More detailed descriptions of these have already been published in American periodicals, ${ }^{12}$

10 This has since been published in the British Medical Journal, 10 This has since been published in the British Medical Jour
Oct. 29th, 1898. Turck: Pneumatic Gymmastics of the Stomach.

Oct. 29th, 1898. Turck: Pneumatic Gymnastics of the Stomach.
II An ordinary rubber bulb the same as used for producing a spray II An ordinary rubber bulb the same as used for pro
may be used, but is not as effectual as compressed air.

may be used, but is not as effectual as compressed air.
12 . Treatment of Chronic Glandular Gastritis: Therapeutic Gazette, 12 1. Treatment of Chronic Glandular Gastritis: Therapeutic Gazette,
Jane 15th, 1895. 2. Glandular Gastritis with Bacteriological Studies Jane 15th, 1895. 2. Glandular Gastritis with Bacteriological Studies of the Pharyngeal Vault: New York Medical Journal, Nov. 23rd, 1895.
3. Methods of Diagnosis and Therapeutics of Diseases of the Stomach
and Intestines : Journal of the American Medical Association, and Intestines: Journal of the American Medical Association, June 22nd, 1895; also New York Medical Journal, Feb. 22nd and
March 7th, 1896. 4. The Etiology and Pathology of Gastritis upon which is based Rational Therapeutics: Chicago Clinical Review, December, 1895, and January, 1896. 5. Gastritis Glandularis Chronica Medical News, April 4th, 1896. 6. A Bipolar Stomach Electrode Medical News, 1896, p. 240. 7. Modern Method of Treatment of Diseases of the Intestines: New York Medical Joumal, Feb. 7 th and March 13th and 20th, 1897. 8. Surgical Shock: Journal of the American Medical Association, 1897, p. 1160. 9. Experiments and Technique of a New Hydrotherapeutic Method: Louisville Journal of Surgery, July, 1898. 10. The Intra-gastric Reagent Capsule: Journal of the American Medical Association, April $23 \mathrm{rd}, 1898$. but constant use naturally gives rise to modifications and improvements of instruments and methods. Some such, at present on trial, it is hoped can be reported upon in the near future, also some other points not touched upon here.

\section{THE PRESENT POSITION OF THE QUESTION OF OPERATION IN UTERINE FIBROIDS. ${ }^{1}$}

\section{BY E. STANMORE BISHOP, F.R.C.S. ENG., SURGEON TO THE ANCOATS HOSPITAI, MANCHESTER.}

ALTHOUGH the consideration of this subject appears at first sight more fitted for a society of gynæcologists than for a clinical society it is well sometimes to report progress in any special work to those wbose professional duties necessitate a more general range of information. During the last few years the surgical treatment of fibroid disease of the uterus has undergone considerable change and necessarily consequent upon this the general question as to what advice shall be given to a patient suffering from this disease has assumed new aspects. Speaking generally I believe it may be said that the usual feeling of both patients and the bulk of the medical profession is against active interference in these cases and that this feeling is based upon four reasons: (1) fibroids are not fatal if left alone ; (2) fibroids can be made to shrink by the use of ergot and similar drugs; (3) fibroids naturally tend to disappear at the menopause; and (4) surgical interference if it is to be effective imports extreme risk to life. The relative value of the first three depends very greatly upon the amount of force which attaches to the fourth. If this is less true than it undoubtedly was they lose much of their importance, whilst a new set of reasons for operation which previously could scarcely be maintained now become evident and gain in weight in proportion to the amount of change which can be shown.

Before the introduction of asepsis into surgery the mortality of any operation for the removal of fibroid can hardly be said to have existed, since no such operation could safely be undertaken. The course of events has been greatly like that of ovariotomy. Since any new operation must necessarily be somewhat of an experiment it was only in extremely bad cases at first that anything was tried. This meant, of course, that the tumours present were exceptionally large and the prospect of removing them was correspondingly gloomy. Subperitoneal fibroids with a pedicle were removed if single. Submucous fibroids, also pedunculated and those which had become polypoid were taken away, but interstitial fibroids, especially if multiple, were carefully left alone. If the tumour projected sufficiently towards the uterine canal, this was dilated, the capsule divided, and the tumour either enucleated at once or allowed to gradually extrude itself. If the first was possible recovery often followed, but if the latter the risks of gangrene of the tumour were very great. Tait had 8 cases of this kind with 4 deaths. The operation then most in favour-due, no donbt, to his powerful adrocacy - was removal of the ovaries and tubes. In his latest book he gives a list of 262 cases with $4^{\circ}$ deaths, exclusive of his earlier cases which had a mortality of nearly 25 per cent. The latter list, it will be seen, has a mortality of only 1.53 per cent. The mortality in Thornton's hands was just over 4 per cent. Such a mortality is certainly low enough to demonstrate the safety of the operation, but the mere mortality is not of course the only point to be considered even if in other hands it could have been maintained. Of far more importance is the effectiveness of the operation and its ultimate result. The result of this method as a rule was a decrease in the size of the tumour and cessation of flooding, but this did not follow in all cases. In some the tumour not only did not decrease, but it went on enlarging, and especially was this the case in fibro-cystic tumours. These apparently were not amenable to this operation at all. Unfortunately these were precisely the tumours which gave most trouble, caused the greatest loss of blood, and as to which even the normal menopause could not be relied upon to give relief. Moreover, in many

1 A paper read before the Clinical Society of Manchester on Jan. 17th, 